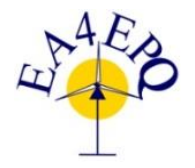

International Conference on Renewable Energies and Power Quality (ICREPQ'15)

$$
\begin{aligned}
& \text { La Coruña (Spain), 25 } 5^{\text {th }} \text { to } 27^{\text {th }} \text { March, } 2015 \\
& \text { Renewable Energy and Oourer Qualiuy. Yournal (RE\&PQJ) } \\
& \text { ISSN 2172-038 X, No.13, April } 2015
\end{aligned}
$$

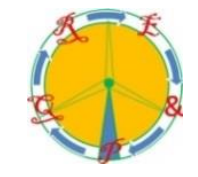

\title{
A Comparative Analysis between Methodologies for Responsibility Assignment on Harmonic Distortions
}

\author{
A. C. Santos ${ }^{1}$, J. C. Oliveira ${ }^{1}$ and I. N. Santos ${ }^{1}$ \\ ${ }^{1}$ Faculty of Electrical Engineering \\ Federal University of Uberlandia (UFU) \\ Campus Santa Mônica - Av. João Naves de Ávila, 2121. Postcode: 38400-902 - Uberlandia (Brazil) \\ Phone: +55 343239 4733, e-mail: andreia.crico@gmail.com, jcoliveira@ufu.br, ivan@ieee.org
}

\begin{abstract}
A current challenge which emanates from the Power Quality area is the search for a reliable means for sharing the responsibility assignment on harmonic distortions between the parties involved. In fact, to determine the THD (Total Harmonic Distortion) levels for the points of coupling between the suppliers and consumers, the identification of the individual contributions of the parties is presented as information relevant to any mitigating measures. In this context, although in literature there have been some highlighted methodologies, which aim at characterizing portions of responsibility between the agents, due to the subjects concerning the procedures, there are still frequent questionnaires concerning the conclusive contribution from the parties. Thus, this article summarizes the main procedures found in literature and through the implementation of a hypothetical test system that operates under three distinct conditions, a set of performance computational studies are carried out. The studies yield results that are utilized as a comparative and critical base of the methodologies being directed towards the motives described herein, while highlighting their potential along with limitations.
\end{abstract}

\section{Key words}

Harmonic sources, harmonic distortion, sharing of responsibility.

\section{Introduction}

The theme of harmonic distortion, inserted into the context of Power Quality, raises questions that are receiving ever greater prominence on the world's energy stages. It can be stated that this fact is a consequence of the significant changes that have happened to the operating characteristics of electrical systems with a huge intensification in the number of non-linear loads, primarily from the second half of the twentieth century.

In light of the various harmful effects that the presence of harmonic distortion can cause, there has been a gradual inclination towards standards and recommendations that have sought to set limits designed to maintain the standards of power quality at acceptable levels. In particular, regarding the subject of harmonic distortions, one can cite: IEEE Standard 519 [1], IEC 61000-3-6 [2] e EN 50160 [3].

However, it can be recognized that until the present moment existing documents do not make reference to mechanisms capable of determining where at a particular point or along a specific measurement bus, sit the percentages of responsibility to be assigned to the supplier and consumer systems. Notwithstanding this, the search for means to provide such needs assumes importance the moment that it becomes necessary to implement mitigating solutions, which will imply generated financial costs. If this is the case, the responsibility for which should be identified and justly shared between the parties involved. Thus, it appears that this issue is worthy of a methodology that proves itself to be reliable, robust and consistent in order to avoid arbitrariness and disagreements among the agents involved.

As one opens up to the scenario presented by literature one finds procedures that propose the allocation of responsibility for harmonic distortion, from among which the following can be cited: the Method of Harmonic Power Flow [4], [5], the Method of Conforming and Non-Conforming Current [6], [7], the Superposition Method [8], [9] and The Frequency Spectra Analysis Method [10], as well as other proposals [11], [12]. However, concerning the first three methods there are indications of inconsistencies, inaccuracies or difficulties in terms of their practical application [13], [14], [15]. On the other hand, the methodology denominated herein as The Frequency Spectra Analysis, consists of a relatively recent proposal, and for this reason inspires special interest.

In this sense, this study aims at carrying out a comparative analysis between the performances of the four previously cited methodologies. Mathematical and computational investigations are conducted in a test system representing a typical distribution feeder, for reaching this goal. Thus, the subsequent studies are directed towards the following focal points: 
- Presentation of the theoretical basis of the methods under consideration;

- Application of computational framework methods using a test system with features that are consonants to real systems;

- Analysis of results and establishing conclusive terms on the appropriateness of the methods evaluated herein.

\section{Fundamentals on the Methods for the Assignment of Responsibilities in Harmonic Distortion}

\section{A. Harmonic Power Flow Method}

The Harmonic Power Flow Method is based on the relationship that exists between the network's active harmonic power flow direction and the direction of the active power flow of fundamental frequency [4]. The methodology in question does not permit the proportional separation of responsibilities, but indicates the predominant direction of harmonic source.

The active harmonic power for a particular order $\mathrm{h}$ can be obtained as shown in (1).

Where:

$$
P_{h}=V_{h} \cdot I_{h} \cdot \cos \phi_{h}
$$

$\mathrm{P}_{\mathrm{h}}=$ active harmonic power of the order $\mathrm{h}$;

$\mathrm{V}_{\mathrm{h}}=$ harmonic voltage module of the order $\mathrm{h}$;

$\mathrm{I}_{\mathrm{h}}=$ harmonic current module of the order $\mathrm{h}$;

$\phi_{\mathrm{h}}=$ angular or phase difference of the order $\mathrm{h}$.

In the absence of internal consumer production, the flow direction of the active power of fundamental frequency is adopted as positive. Therefore, from the angle $\phi_{\mathrm{h}}$ it is possible to obtain the harmonic power signal and in accordance with classic principles, one has:

- $\quad-90^{\circ}<\phi_{\mathrm{h}}<90^{\circ}$ : in this case active harmonic power has a positive signal and the supplier acts as a generator of the order in question;

- $90^{\circ}<\phi_{\mathrm{h}}<270^{\circ}$ : in this case, on the other hand the active harmonic power presents a negative signal and the consumer acts as the generator of the considered order.

\section{B. Conforming and Non-Conforming Current Method}

The Conforming and Non-Conforming Current Method suggests the classification of consumer loads as those which produce no additional distortions to those already present on the voltage supply (Group I) and those which produce additional distortions to those originally present on the supply voltage (Group II). In this manner, for each frequency $\omega$, the total current (I) can be represented by the addition between the portion of load supply from Group I, or the conforming portion $\left(\dot{\mathrm{I}}_{\mathrm{c}}\right)$, and the supply portion of the loads in Group II, or the non-conforming portion $\left(\dot{\mathrm{I}}_{\mathrm{nc}}\right)$, as indicated in (2) [6].

$$
\dot{I}(\omega)=\dot{I}_{c}(\omega)+\dot{I}_{n c}(\omega)
$$

Paying attention to the fact the Non-Conforming current is null for the fundamental frequency $\left(\omega_{1}\right)$ and taking on the assumption that the loads for Group I possess the same impedance for all evaluated frequencies, the development of the methodology inclines towards the Conforming and NonConforming portions of current, as shown in (3) e (4).

$$
\begin{gathered}
\dot{I}_{c}(\omega)=\frac{\dot{I}\left(\omega_{1}\right)}{\dot{V}\left(\omega_{1}\right)} \cdot \dot{V}(\omega) \\
\dot{I}_{n c}(\omega)=\dot{I}(\omega)-\frac{\dot{I}\left(\omega_{1}\right)}{\dot{V}\left(\omega_{1}\right)} \cdot \dot{V}(\omega)
\end{gathered}
$$

Finally, with the aim of allocating responsibility where harmonic distortions are concerned, the process considers that the contributing portions are directly associated to the existing portions between the Conforming and NonConforming currents for each frequency.

\section{Superposition Method}

For the application of the Superposition Method, a representative circuit system is used, as illustrated in Fig. 1, for each harmonic order under review.

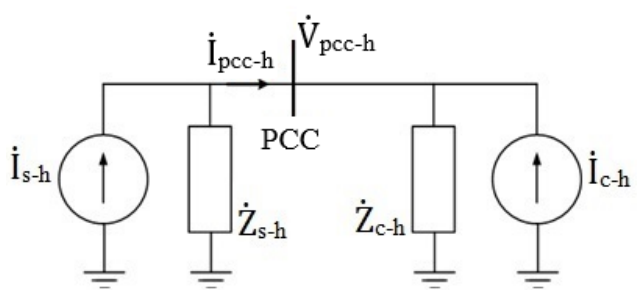

Fig. 1. Norton equivalent circuit for a given harmonic order $h$

In Fig. 1:

$$
\begin{aligned}
& \text { PCC = Point of Common Coupling; } \\
& \dot{\mathrm{I}}_{\text {pcc-h }}=\text { PCC harmonic current; } \\
& \dot{\mathrm{V}}_{\text {pcc-h }}=\text { PCC harmonic voltage; } \\
& \dot{\mathrm{I}}_{\mathrm{s}-\mathrm{h}}=\text { harmonic current generated by the supply } \\
& \text { which refers to supplier circuit; } \\
& \dot{\mathrm{I}}_{\mathrm{c}-\mathrm{h}}=\text { harmonic current generated by the supply } \\
& \text { which refers to consumer circuit; } \\
& \dot{\mathrm{Z}}_{\mathrm{s}-\mathrm{h}}=\text { harmonic impedance referring to the supplier } \\
& \text { circuit; } \\
& \dot{\mathrm{Z}}_{\mathrm{c}-\mathrm{h}}=\text { harmonic impedance referring to the } \\
& \text { consumer circuit. }
\end{aligned}
$$

Based on the analysis of the Norton equivalent circuit and making use of the classic principles of circuit superposition, it is possible to determine the contributions of harmonic current on the PCC coming from the supplier system $\left(\dot{\mathrm{I}}_{\mathrm{s}-\mathrm{pcc}-\mathrm{h}}\right)$, and from the consumer ( $\left.\dot{\mathrm{I}}_{\mathrm{c}-\mathrm{pcc}-\mathrm{h}}\right)$ [8]. As a consequence, as 
indicated in (5), the total current load on the PCC can be obtained through the phasors addition of such components.

$$
\dot{I}_{p c c-h}=\dot{I}_{s-p c c-h}+\left(-\dot{I}_{c-p c c-h}\right)
$$

Finally, the method of superposition of currents requires the sharing of responsibilities between the parties must be carried out through the phasor projection values representing the individual current contributions ( $\dot{\mathrm{I}}_{\text {s-pcc-h }}$ and $\left.\dot{\mathrm{I}}_{\mathrm{c}-\mathrm{pcc}-\mathrm{h}}\right)$ on the total phasor current at the PCC $\left(\dot{\mathrm{I}}_{\mathrm{pcc}-\mathrm{h}}\right)$.

\section{Frequency Spectra Analysis Method}

The Frequency Spectra Analysis Method considers the initial point that a pure resistive load can be considered a nonpolluting ideal load, once that in this case the voltage and current waveforms are identical.

The methodology establishes that the voltage and current waveforms are normalized and decomposed into Fourier series, thus obtaining the quantities $\dot{\mathrm{I}}_{\mathrm{n}-\mathrm{h}}$ and $\dot{\mathrm{V}}_{\mathrm{n}-\mathrm{h}}$, which are, respectively, current and voltage normalized on the PCC for a given harmonic order $h$. The voltage $\dot{V}_{n-h}$ once normalized goes on to be denominated as $\dot{\mathrm{I}}_{\text {un-h. }}$ Under these circumstances, it is possible to obtain the quantities denominated as $\dot{\mathrm{I}}_{\mathrm{cn}-\mathrm{h}}$, which represents the difference between the phasors $\dot{I}_{n-h}$ and $\dot{I}_{\text {un-h }}$, as shown in (6). The method affirms that such a difference is null only for the case where the load is purely resistive and as a consequence $\dot{I}_{c n-h}$ represents the PCC current derived from the consumer system [10].

$$
\dot{I}_{c n-h}=\dot{I}_{n-h}-\dot{I}_{u n-h}
$$

From the retrieval of the $\dot{\mathrm{I}}_{\mathrm{un}-\mathrm{h}}, \dot{\mathrm{I}}_{\mathrm{n}-\mathrm{h}}$ and $\dot{\mathrm{I}}_{\mathrm{cn}-\mathrm{h}}$ phasors, the method articulates that supplier contributions ( $\left.\mathrm{I}_{\mathrm{s}-\mathrm{contr}-\mathrm{h}}\right)$ and the consumer $\left(\mathrm{I}_{\mathrm{c}-\mathrm{contr}-\mathrm{h}}\right)$ can be determined from (7) and (8), respectively.

$$
\begin{aligned}
& I_{s-\text { contr }-h}=\left|\dot{I}_{u n-h}\right| \cdot \cos \alpha \\
& I_{c-\text { contr }-h}=\left|\dot{I}_{c n-h}\right| \cdot \cos \beta
\end{aligned}
$$

Where:

$$
\begin{aligned}
& \alpha=\text { angle between the phasors } \dot{\mathrm{I}}_{\mathrm{un}-\mathrm{h}} \text { and } \dot{\mathrm{I}}_{\mathrm{n}-\mathrm{h}} \\
& \beta=\text { angle between the phasors } \dot{\mathrm{I}}_{\mathrm{cn}-\mathrm{h}} \text { and } \dot{\mathrm{I}}_{\mathrm{n}-\mathrm{h}} .
\end{aligned}
$$

So, as to better understand the philosophy behind the method, in Fig. 2 the phasors involved in the procedure are shown, as indicated in [10].

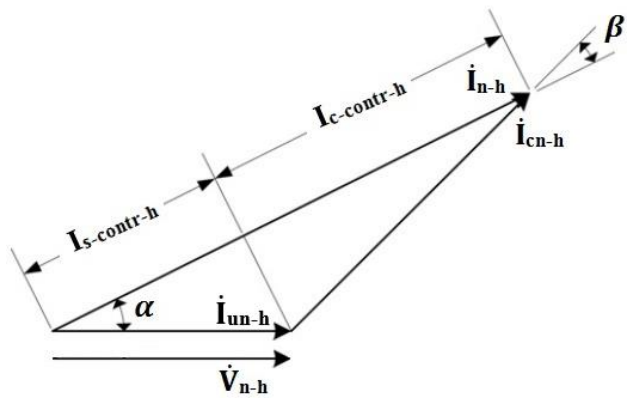

Fig. 2. Representation of phasors normalized to an order $h$.

\section{Test system and cases considered for the computational comparative studies}

\section{A. Electric Test System}

The studies proposed in this work were realized by means of computer simulations. The characteristics of the test system used search for a representation of a consumer unit with resistive loads (incandescent lamps, heaters, etc.), capacitive loads (capacitor bank), inductive loads (motors) and special loads (rectifiers, velocity controllers, etc.). This arrangement is typically found in distribution feeders.

It is noteworthy that, for the purpose of this study, the supply system was taken as that consisting of a single-phase AC source and impedance defined by the local busbar short circuit level. The consumer system, as already mentioned, is characterized by the parallel combination of linear loads (resistor, inductor and capacitor) and non-linear loads (represented by the current source of whole multiples of the fundamental frequency).

Table I presents the information necessary for the parameterisation of the test system used. It is worth noting that the data refers to a three-phase arrangement, whilst the work was carried out on only one of the phases, as previously mentioned.

Table I. Parameters of the electric system components

\begin{tabular}{|c|c|}
\hline Description & Parametrization \\
\hline Voltage level & $13.8 \mathrm{kV}$ \\
\hline $\begin{array}{c}\text { Three-phase Busbar Short } \\
\text { Circuit Level }\end{array}$ & $6,32 \mathrm{MW}$ \\
\hline $\begin{array}{c}\text { Load Three-phase Active } \\
\text { Power }\end{array}$ & $2,7 \mathrm{MVAr}$ \\
\hline $\begin{array}{c}\text { Load Three-phase Inductive } \\
\text { Power }\end{array}$ & $1 \mathrm{MVAr}$ \\
\hline $\begin{array}{c}\text { Load Three-phase Capacitive } \\
\text { Power }\end{array}$ & $\begin{array}{c}\text { Represented by a harmonic } \\
\text { current sources }\end{array}$ \\
\hline Non-Linear load
\end{tabular}

With the data listed in table I at hand, it was possible to elaborate the arrangement used for simulation purposes, and which gave rise to the electric circuit presented in Fig. 3. To this end, as shown in the figure, the ATP (Alternative Transients Program) simulator was used as a basis for the computer studies.

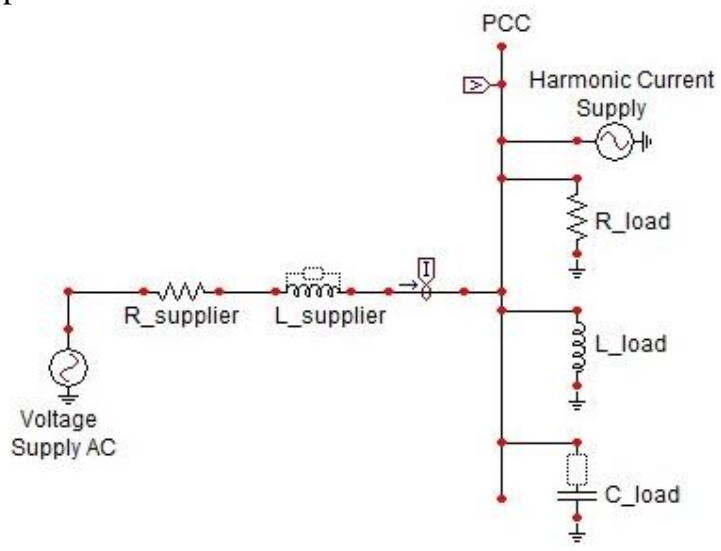

Fig. 3. Physical arrangement used in performance tests. 
In Fig. 3 the following terms were used:

AC supply voltage;

R_supplier - resistance of the supplier system;

L_supplier - inductance of the supplier system;

R_load - Load resistance;

L_load - Load inductance;

C_load - Load capacitance;

Harmonic Current Supply - representing the presence of non-linear loads.

\section{B. Studied Cases}

In order that the methodology performance evaluation is able to cover the consonants operational conditions as existing possibilities in real systems, it was considered pertinent to carry out simulations that refer to the three hypothetical conditions, as described in the following.

1) Condition 1: purely sinusoidal voltage supply and a consumer containing linear and non-linear loads.

In this case, the presence of non-linear loads was represented by injecting currents of harmonic frequency into the system. Table II shows the features of the current source used.

Table II. Parameters of the used current source

\begin{tabular}{|c|c|}
\hline Frequency $[\mathrm{Hz}]$ & Current $[\mathrm{A}]$ \\
\hline 180 & $19,80 \angle 85^{\circ}$ \\
\hline 300 & $51,62 \angle 12^{\circ}$ \\
\hline 420 & $21,92 \angle 63^{\circ}$ \\
\hline
\end{tabular}

Under these circumstances, table III presents the voltage and current harmonics phase values obtained on the PCC.

Table III. current and voltage PCC values obtained for computational simulation for condition 1

\begin{tabular}{|c|c|c|}
\hline $\begin{array}{c}\text { Harmonic } \\
\text { Order }\end{array}$ & Quantity & Value \\
\hline \multirow{2}{*}{$\mathbf{1}^{\mathbf{a}}$} & $\mathrm{V}$ & $7793 \angle-2,76^{\circ} \mathrm{V}$ \\
\cline { 2 - 3 } & $\mathrm{I}$ & $267,9 \angle-17,64^{\circ} \mathrm{A}$ \\
\hline \multirow{2}{*}{$\mathbf{3}^{\mathbf{a}}$} & $\mathrm{V}$ & $92,07 \angle 165,6^{\circ} \mathrm{V}$ \\
\cline { 2 - 3 } & $\mathrm{I}$ & $20,29 \angle-100,7^{\circ} \mathrm{A}$ \\
\hline \multirow{2}{*}{$\mathbf{5}^{\mathbf{a}}$} & $\mathrm{V}$ & $572,9 \angle 79,85^{\circ} \mathrm{V}$ \\
\cline { 2 - 3 } & $\mathrm{I}$ & $60,04 \angle 173^{\circ} \mathrm{A}$ \\
\hline \multirow{2}{*}{$\mathbf{7}^{\mathbf{a}}$} & $\mathrm{V}$ & $407 \angle 114,4^{\circ} \mathrm{V}$ \\
\cline { 2 - 3 } & $\mathrm{I}$ & $30,85 \angle-152,8^{\circ} \mathrm{A}$ \\
\hline
\end{tabular}

In accordance with the characteristics established in this condition, the full responsibility for the harmonic distortions on the PCC should be placed on the consumer.

2) Condition 2: supply voltage with a predefined distortion standard and a consumer containing only linear loads.

To simulate these conditions, components of the fifth and seventh harmonic order were added to the fundamental voltage frequency of the system's supply source, as indicated in table IV.
Table IV. Parameters of the voltage source used

\begin{tabular}{|c|c|}
\hline Frequency $[\mathrm{Hz}]$ & Voltage $[\mathrm{V}]$ \\
\hline 60 & $7967,43 \angle 0^{\circ}$ \\
\hline 300 & $717,07 \angle 25^{\circ}$ \\
\hline 420 & $597,55 \angle 81^{\circ}$ \\
\hline
\end{tabular}

Thus, the voltage and current harmonic phase values obtained on the PCC for the condition 2 are presented in table V.

Table V. Current and Voltage PCC Values Obtained by Computer Simulation for Condition 2

\begin{tabular}{|c|c|c|}
\hline $\begin{array}{c}\text { Harmnonic } \\
\text { Order }\end{array}$ & Quantity & Value \\
\hline \multirow{2}{*}{$1^{\mathbf{a}}$} & $\mathrm{V}$ & $7791 \angle-2,73^{\circ} \mathrm{V}$ \\
\cline { 2 - 3 } & $\mathrm{I}$ & $267,9 \angle-17,79^{\circ} \mathrm{A}$ \\
\hline \multirow{2}{*}{$\mathbf{5}^{\mathbf{a}}$} & $\mathrm{V}$ & $848,9 \angle 5,52^{\circ} \mathrm{V}$ \\
\cline { 2 - 3 } & $\mathrm{I}$ & $34,43 \angle 39,7^{\circ} \mathrm{A}$ \\
\hline \multirow{2}{*}{$\mathbf{7}^{\mathbf{a}}$} & $\mathrm{V}$ & $845 \angle 44,7^{\circ} \mathrm{V}$ \\
\cline { 2 - 3 } & $\mathrm{I}$ & $40,55 \angle 90,57^{\circ} \mathrm{A}$ \\
\hline
\end{tabular}

Evidently, in this condition the full responsibility for the harmonic distortions falls upon the supplier.

3) Condition 3: supply voltage with a predefined distortion standard and the consumer containing linear and non-linear loads.

In order to analyse these circumstances the characteristics of conditions 1 and 2 were simultaneously imposed. In this manner, the voltage and current phase harmonics on the PCC for condition 3 are presented in table VI.

Table VI. Current and Voltage PCC Values Obtained by Computer Simulation for Condition 3

\begin{tabular}{|c|c|c|}
\hline $\begin{array}{c}\text { Harmonic } \\
\text { Order }\end{array}$ & Quantity & Value \\
\hline \multirow{2}{*}{$\mathbf{1}^{\mathbf{a}}$} & $\mathrm{V}$ & $7792 \angle-2,79^{\circ} \mathrm{V}$ \\
\cline { 2 - 3 } & $\mathrm{I}$ & $268 \angle-17,75^{\circ} \mathrm{A}$ \\
\hline \multirow{2}{*}{$\mathbf{3}^{\mathbf{a}}$} & $\mathrm{V}$ & $99,52 \angle 170^{\circ} \mathrm{V}$ \\
\cline { 2 - 3 } & $\mathrm{I}$ & $20,98 \angle-100,9^{\circ} \mathrm{A}$ \\
\hline \multirow{2}{*}{$\mathbf{5}^{\mathbf{a}}$} & $\mathrm{V}$ & $1134 \angle 34,64^{\circ} \mathrm{V}$ \\
\cline { 2 - 3 } & $\mathrm{I}$ & $44,55 \angle 138,8^{\circ} \mathrm{A}$ \\
\hline \multirow{2}{*}{$\mathbf{7}^{\mathbf{a}}$} & $\mathrm{V}$ & $1053 \angle 66,28^{\circ} \mathrm{V}$ \\
\cline { 2 - 3 } & $\mathrm{I}$ & $38,62 \angle 136,8^{\circ} \mathrm{A}$ \\
\hline
\end{tabular}

The analysis of the previous cases allows for the inference that in condition 3, the distortions of order three are exclusively placed on the consumer, while the distortion of fifth and seventh orders have shared responsibilities between the parties, which were predominantly proceeding from the consumer and supplier respectively.

\section{Methodology Performance Analysis for the Investigated Cases}

\section{A. Harmonic Power Flow Method}

Table VII shows the results achieved after applying the Harmonic Power Flow Method. 
Table VII. Results from the Application of the Harmonic Power Flow Method

\begin{tabular}{|c|c|c|c|}
\hline Condition & $\begin{array}{l}\text { Harmonic } \\
\text { Order }\end{array}$ & $\begin{array}{l}\text { Active Harmonic } \\
\text { Power [W] }\end{array}$ & Power Angle \\
\hline \multirow{4}{*}{1} & $1^{\mathrm{a}}$ & 2017733,80 & $14,88^{\circ}$ \\
\hline & $3^{a}$ & $-120,55$ & $266,3^{\circ}$ \\
\hline & $5^{\mathrm{a}}$ & $-1890,12$ & $-93,15^{\circ}$ \\
\hline & $7^{\mathrm{a}}$ & $-613,36$ & $267,2^{\circ}$ \\
\hline \multirow{3}{*}{2} & $1^{\mathrm{a}}$ & 2015522,17 & $15,06^{\circ}$ \\
\hline & $5^{\mathrm{a}}$ & 24179,34 & $-34,18^{\circ}$ \\
\hline & $7^{a}$ & 23858,16 & $-45,87^{\circ}$ \\
\hline \multirow{4}{*}{3} & $1^{\mathrm{a}}$ & 2017477,24 & $14,96^{\circ}$ \\
\hline & $3^{\mathrm{a}}$ & 32,80 & $270,9^{\circ}$ \\
\hline & $5^{a}$ & $-12358,66$ & $-104,16^{\circ}$ \\
\hline & $7^{\mathrm{a}}$ & 13561,49 & $-70,52^{\circ}$ \\
\hline
\end{tabular}

The values presented in the previous table show that for condition number 1 the active harmonic power flows, which refer to orders 3, 5 and 7, are found to be in opposition to that of the fundamental power. These results ratify the expectations, as the harmonic components responsible are physically linked to the load, or be it; they are the responsibility of the consumer.

On the other hand, in accordance with the requirements of condition 2, the method indicates that all existing harmonics originate from the supplier system.

In condition 3, as expected, the results indicate that the powers of the orders 5 and 7 are predominantly derived from the consumer and supplier system, respectively. However, one notices an inconsistency in attributing responsibility over the third order to the supplier. As already known, the distortions of such a frequency are the full responsibility of the load.

The stated imprecision can occur due to the fact that the harmonic power magnitudes are very small, when compared to the fundamental value. Besides this, as lags of $\pm 90^{\circ}$ correspond to the limit of the decision process, any higher or lower deviation can lead to interpretation errors concerning the predominant directionality in the characterization of harmonic distortions.

\section{B. Conforming and Non-Conforming Current Method}

The application of the Conforming and Non-Conforming Current Method leads to the results presented in table VIII.

Table VIII. Results from the Application of the Conforming and Non-Conforming Current Method

\begin{tabular}{|c|c|c|c|c|c|}
\hline \multirow{2}{*}{ Condition } & \multirow{2}{*}{$\begin{array}{c}\text { Harmonic } \\
\text { Order }\end{array}$} & \multicolumn{2}{|c|}{ Conforming Current } & \multicolumn{2}{|c|}{$\begin{array}{c}\text { Non-Conforming } \\
\text { Current }\end{array}$} \\
\hline & & $\dot{\mathrm{I}}_{\mathrm{c}}[\mathrm{A}]$ & $\%$ & $\dot{\mathrm{I}}_{\mathrm{nc}}[\mathrm{A}]$ & $\%$ \\
\hline \multirow{4}{*}{1} & $1^{\mathrm{a}}$ & $267,9 \angle-17,64^{\circ}$ & 100 & 0 & 0 \\
\hline & $3^{\mathrm{a}}$ & $3,17 \angle 150,72^{\circ}$ & 12,83 & $21,51 \angle-92,68^{\circ}$ & 87,17 \\
\hline & $5^{\mathrm{a}}$ & $19,69 \angle 64,97^{\circ}$ & 22,27 & $68,74 \angle-171,19^{\circ}$ & 77,73 \\
\hline & $7^{\mathrm{a}}$ & $13,99 \angle 99,52^{\circ}$ & 27,15 & $37,55 \angle-132,00^{\circ}$ & 72,85 \\
\hline \multirow{3}{*}{2} & $\mathbf{1}^{\mathrm{a}}$ & $267,9 \angle-17,79^{\circ}$ & 100 & 0 & 0 \\
\hline & $5^{\mathrm{a}}$ & $29,19 \angle-9,54^{\circ}$ & 52,01 & $26,93 \angle 94,89^{\circ}$ & 47,99 \\
\hline & $7^{\mathrm{a}}$ & $29,06 \angle 29,64^{\circ}$ & 44,22 & $36,66 \angle 134,42^{\circ}$ & 55,78 \\
\hline \multirow{4}{*}{3} & $\mathbf{1}^{\mathrm{a}}$ & $268 \angle-17,75^{\circ}$ & 100 & 0 & 0 \\
\hline & $3^{\mathrm{a}}$ & $3,42 \angle 155,04^{\circ}$ & 13,43 & $22,06 \angle-92,24^{\circ}$ & 86,57 \\
\hline & $5^{\mathrm{a}}$ & $39,00 \angle 19,68^{\circ}$ & 35,11 & $72,09 \angle 167,01^{\circ}$ & 64,89 \\
\hline & $7^{\mathrm{a}}$ & $36,22 \angle 51,32^{\circ}$ & 41,61 & $50,82 \angle-177,93^{\circ}$ & 58,39 \\
\hline
\end{tabular}

The previous table easily demonstrates the fragility of the methodology in question. To start with, in condition 1 the method attributed a portion of responsibility to the supplier, when it is known that the distortions are exclusively derived from the consumer.

All the remaining conditions also revealed strong inconsistencies, as the procedure failed by attributing the majority of the responsibility on determined harmonic orders. The observed failures stem from weaknesses inherent to the method, which are felt at the time that loads established, for any frequency, in Group I (linear loads) possess the same impedance. This condition is inconsistent with the principles that govern the functionality of electric circuits.

\section{Superposition Method}

The values obtained from the application of the Superposition Method are shown in table IX.

Table IX. Results from the Application of the Superposition Method

\begin{tabular}{|c|c|c|c|c|c|c|c|}
\hline \multirow{2}{*}{ 节 } & \multirow{2}{*}{ 完 } & \multirow{2}{*}{$\begin{array}{c}\dot{\mathrm{I}}_{\mathrm{s}-\mathrm{pcc}-\mathrm{h}} \\
{[\mathrm{A}]}\end{array}$} & \multirow{2}{*}{$\begin{array}{c}\dot{\mathrm{I}}_{\mathrm{c}-\mathrm{pcc}-\mathrm{h}} \\
{[\mathrm{A}]}\end{array}$} & \multicolumn{2}{|c|}{$\mathrm{I}_{\mathrm{sf}}$} & \multicolumn{2}{|c|}{$\mathrm{I}_{\mathrm{cf}}$} \\
\hline & & & & {$[\mathrm{A}]$} & $\%$ & {$[\mathrm{~A}]$} & $\%$ \\
\hline \multirow{3}{*}{1} & $3^{a}$ & $0,86 \angle 2,49^{\circ}$ & $20,50 \angle 76,96^{\circ}$ & $-0,20$ & 0,95 & 20,49 & 99,05 \\
\hline & $5^{a}$ & $1,04 \angle 13,42^{\circ}$ & $61,02 \angle-6,66^{\circ}$ & $-0,98$ & 1,58 & 61,02 & 98,42 \\
\hline & $7^{a}$ & $1,03 \angle 22,71^{\circ}$ & $31,87 \angle 27,06^{\circ}$ & $-1,02$ & 3,11 & 31,87 & 96,89 \\
\hline \multirow{2}{*}{2} & $5^{a}$ & $34,77 \angle 40,78^{\circ}$ & $0,74 \angle 103,12^{\circ}$ & 34,76 & 99,06 & $-0,33$ & 0,94 \\
\hline & $7^{\mathrm{a}}$ & $40,87 \angle 90,98^{\circ}$ & $0,44 \angle 132,90^{\circ}$ & 40,87 & 99,22 & $-0,32$ & 0,78 \\
\hline \multirow{3}{*}{3} & $3^{\mathrm{a}}$ & $0,74 \angle-18,21^{\circ}$ & $20,90 \angle 77,08^{\circ}$ & 0,09 & 0,45 & 20,89 & 99,55 \\
\hline & $5^{a}$ & $35,02 \angle 40,14^{\circ}$ & $60,67 \angle-6,41^{\circ}$ & $-5,27$ & 9,57 & 49,82 & 90,43 \\
\hline & $7^{\mathrm{a}}$ & $40,85 \angle 90,44^{\circ}$ & $31,35 \angle 27,36^{\circ}$ & 28,19 & 72,99 & 10,43 & 27,01 \\
\hline
\end{tabular}

The results presented in table IX do not show any type of disagreement with what was expected from the three conditions studied. One notes that there were only some subtle deviations in respect to expected values. However, this fact is probably caused by the calculations being rounded up or down or by small inaccuracies in the simulation results. In this sense, the Superposition Method proved satisfactory for the intended purposes, since the efficiency of the process is supported by classical principles related to the superposition of electric circuits. However, it is noteworthy that the major difficulties that may be encountered in practical applications of the methodology are related to the determination of impedances on the suppliers' system, and especially those related with the load, given that these are generally characterized as being very dynamic and hard to be obtained.

\section{Frequency Spectra Analysis Method}

Table $\mathrm{X}$ shows the results obtained from adopting the Frequency Spectra Analysis Method. 
Table IX. Results from the Frequency Spectra Analysis Method

\begin{tabular}{|c|c|c|c|c|c|c|}
\hline \multirow{2}{*}{ نี } & \multirow{2}{*}{ 를 } & \multirow{2}{*}{$\begin{array}{c}\dot{\mathrm{I}}_{\mathrm{cn}-\mathrm{h}} \\
{[\mathrm{A}]}\end{array}$} & \multicolumn{2}{|c|}{$\mathrm{I}_{\mathrm{S}-\mathrm{contr}-\mathrm{h}}$} & \multicolumn{2}{|c|}{$\mathrm{I}_{\mathrm{c}-\mathrm{contr}-\mathrm{h}}$} \\
\hline & & & [A] & $\%$ & [A] & $\%$ \\
\hline \multirow{3}{*}{1} & $3^{a}$ & $0,07 \angle-91,68^{\circ}$ & $-0,0008$ & 1,02 & 0,0740 & 98,98 \\
\hline & $5^{a}$ & $0,23 \angle-168,68^{\circ}$ & $-0,0040$ & 1,79 & 0,2208 & 98,21 \\
\hline & $7^{a}$ & $0,13 \angle-128,28^{\circ}$ & $-0,0025$ & 2,18 & 0,1139 & 97,82 \\
\hline \multirow{2}{*}{2} & $5^{a}$ & $0,07 \angle 98,28^{\circ}$ & 0,0891 & 70,68 & 0,0370 & 29,32 \\
\hline & $7^{a}$ & $0,11 \angle 136,76^{\circ}$ & 0,0746 & 50,28 & 0,0738 & 49,72 \\
\hline \multirow{3}{*}{3} & $3^{a}$ & $0,08 \angle-91,55^{\circ}$ & 0,0002 & 0,26 & 0,0760 & 99,74 \\
\hline & $5^{a}$ & $0,24 \angle 173,92^{\circ}$ & $-0,0349$ & 15,07 & 0,1968 & 84,93 \\
\hline & $7^{a}$ & $0,16 \angle-170,77^{\circ}$ & 0,0442 & 31,50 & 0,0961 & 68,50 \\
\hline
\end{tabular}

Table $\mathrm{X}$ indicates for condition 1 the promising values in relation to those expected, or be it, they confirm the full responsibility for the harmonic distortions over to the consumer. Nevertheless, condition number 2 already shows the allocation of undue portions to the load, which in this case do not generate distortions. Finally, condition 3 reveals a failure in the method even for that part which is predominantly responsible for the seventh order.

Finally, Fig. 4 shows the graph demonstrating the largest error percentage seen in each condition, for the three methodologies that propose the quantification of the portions of responsibility attributed to the agents involved. As predicted, the Superposition Method is the most precise and therefore is highlighted in relation to the others. It is worth noting that the failures related to direction are not identified in the figure, since it comprises of only the largest percentage differences between the quantities found and those expected.

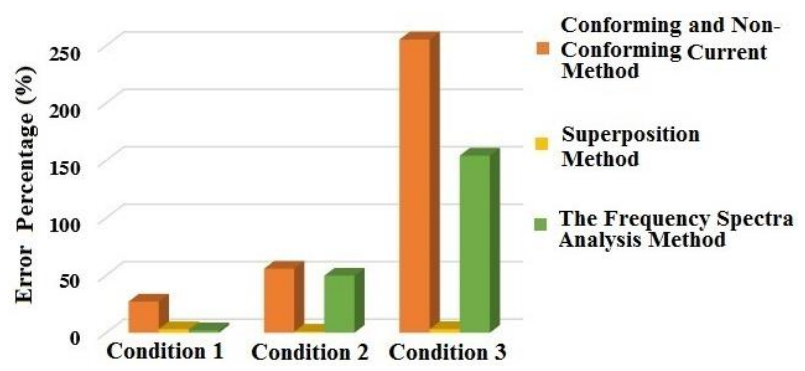

Fig. 4. Error percentage related to the methods.

\section{Conclusion}

This study allocates itself a slot within the context of Method Analysis, which in this case defines the contributions on the part of supplier and consumer for harmonic distortions.

The Harmonic Power Flow Method, which proposes to only define where the greater portion of responsibility falls for the distortions for each harmonic order, showed inconsistencies as to the expected results. Therefore, it became evident that although simple in its methodology, it did not show itself as reliable for any practical application. In addition, the Conforming and Non-Conforming Current Method, which passed on undue responsibilities to the three studied conditions, means that any further comments as to its unworthiness for the task are unnecessary.
The Methodology of Analysis of Frequency Spectra, despite being committed to providing the separation of portions of responsibilities between the consumer and supplier through practical means, proved unsatisfactory in reaching this goal. It was observed that even for less complex conditions it was shown to have considerable failures.

On the other hand, when it comes to the Superposition Method, the obtained results were clear in the sense that they show a physical consistency across the process, as well as the indicators being fully in line with the expected physical performance. However, the difficulty in specifying the value of the impedances for the supplier system, and especially the consumer system is still a fact that may hinder the application of the method in real cases.

Therefore, although the need for additional studies arises for the development of improved models concerning the definition of impedances, the Superposition Method was the only procedure that offered sufficient consistency to inspire breakthroughs that are necessary in this field of research.

\section{References}

[1] IEEE Recommended Practice and Requirements for Harmonic Control in Electric Power Systems, IEEE Standard 519-1992.

[2] Voltage characteristics of electricity supplied by public distribution systems, European Standard EN 50160:1999.

[3] Electromagnetic Compatibility (EMC) - Part 3: Limits - Section 6: Assessment of emission limits for distorting loads in MV and $\mathrm{HV}$ power systems - Basic EMC publication, IEC 61000-3-6, 1996.

[4] T. Tanak, H. Akagi, "A new method of harmonic power detection based on the instantaneous active power in three-phase circuits", IEEE Transactions on Power Delivery, v. 10, n. 4, p. 1737-1742, 1995.

[5] P. H. Swart, M. J. Case, J. D. van Wyk, "On techniques for localization of sources producing distortion in three-phase networks", European Transactions on Electrical, v. 6, n. 6, p. 391-396, 1996.

[6] K. Srinivasan, "On separating customer and supply side harmonic contributions", IEEE Transactions on Power Delivery, v. 11, n. 2, April 1996.

[7] K. Srinivasan e R. Jutras, "Conforming and non-conforming current for attributing steady state power quality problems", IEEE Transactions on Power Delivery, v. 13, n. 1, January 1998.

[8] W. Xu, Y. Liu, "A method for determining customer and utility harmonic contributions at the point of common coupling", IEEE Transactions on Power Delivery, v. 15, n. 2, p. 804-811, 2000.

[9] W. Xu, Y. Liu, "A method to determine customer harmonic contributions for incentive-based harmonic control applications", IEEE Panel on Harmonic Measurements and Allocation, p. 361-366, 1999.

[10] F. M. Fernandez, P. S. Chandramohanan Nair, "Method for separation of customer and utility contributions of harmonics at point of common coupling", IET Generation, Transmission \& Distribution, v. 7, n. 4, p. 374381, 2013.

[11] I. N. Santos, J. C. Oliveira, J. R. Macedo Jr., "Modified superposition method as a new approach to assigning responsibilities on harmonic distortions", Sba Controle \& Automação, v. 23, n. 6, Campinas, 2012.

[12] T. M. Soares, "Estimating the Contribution of Multiple Harmonic Sources using Non Parametric Regression", Master's dissertation, Institute of Technology, Federal University of Para, 2012.

[13] I. N. Santos, J. C. Oliveira, S. F. P. Silva, "Critical evaluation of the performance of the method of harmonic power flow to determine the dominant source of distortion", IEEE Latin America Transactions, v. 9, n. 5, p. 740-746, 2011.

[14] I. N. Santos, J. C. Oliveira, "Critical Analysis of the Current and Voltage Superposition Approaches at Sharing Harmonic Distortion Responsibility”, IEEE Latin America Transactions, v. 9, n. 4, 2011.

[15] I. N. Santos, "A contribution to the evaluation of the principal methods for responsibilities assignment on harmonic distortion". Master's dissertation, Federal University of Uberlandia, 2007. 